\title{
INDEPENDENCE, INTEGRITY, PROFESSIONAL SKEPTISM, CULTURE, COMPETENCY AND QUALITY OF REPORT ON THE RESULTS OF REGIONAL INSPECTORATE EXAMINATION OF SUBANG DISTRICT
}

\author{
Icih $^{1^{*}}$, Lintang Riyunti ${ }^{2}$ \\ 1, 2 Sekolah Tinggi Ilmu Ekonomi Sutaatmadja, Subang \\ *icih@stiesa.ac.id
}

\begin{tabular}{l} 
INFO ARTIKEL \\
\hline Histori Artikel : \\
Tgl. Masuk : 01 September 2020 \\
Tgl. Diterima : 29 September 2020 \\
Tersedia Online : 29 September 2020 \\
\hline Keywords: \\
Independensi, Integritas, Budaya dan \\
Kompetensi.
\end{tabular}

ABSTRAK

Sistem Pengendalian Intern merupakan salah satu kriteria dalam pemeriksaan laporan keuangan pemerintah daerah. Pelaksanaan Sistem Pengendalian Internal Pemerintah (SPIP) merupakan peran penting dari Aparat Pengawas Intern Pemerintah (APIP).Inspektorat Daerah merupakan Aparat Pengawas Intern Pemerintah. Inspektorat Daerah sangat berperan dalam peningkatan opini audit laporan keuangan pemerintah daerah. Perolehan opini audit Wajar Tanpa Pengecualian terhadap laporan keuangan pemerintah daerah Kabupaten Subang dari tahun 2014 sampai dengan 2019 baru tercapai 33\%. Efektivitas pengawasan yang dilakukan oleh inspektorat daerah dapat dilihat berdasarkan kualitas Laporan Hasil Pemeriksaan. Penelitian ini bertujuan untuk mengetahui pengaruh independensi, integritas, skeptisisme profesional, budaya dan kompetensi terhadap kualitas laporan hasil pemeriksaan Inspektorat Daerah Kabupaten Subang baik secara parsial maupun simultan. Penelitian ini menggunakan metode survei dan populasinya adalah seluruh pegawai Inspektorat Daerah Kabupaten Subang. Data yang digunakan terdiri dari data primer yang berasal dari penyebaran kuesioner kepada pegawai Inspektorat Daerah Kabupaten Subang. Analisis data yang digunakan adalah analisis SEM (Structural Equation Modeling) dengan Software SmartPLS versi 3.0. Hasil dari penelitian ini adalah sebagai berikut: (1) variable independensi, integritas, skeptisisme profesional dan kompetensi berpengaruh terhadap kualitas laporan hasil pemeriksaan Inspektorat Daerah Kabupaten Subang , (2) variabel budaya tidak berpengaruh terhadap kualitas laporan hasil pemeriksaan Inspektorat Daerah Kabupaten Subang (3) variabel independensi, integritas, skeptisisme profesional, budaya dan kompetensi secara simultan berpengaruh terhadap kualitas laporan hasil pemeriksaan Inspektorat Daerah Kabupaten Subang.

\section{PENDAHULUAN}

Kekuasaan pengelolaan keuangan negara merupakan salah satu kekuasaan pemerintahan yang dipegang oleh
Presiden sebagai Kepala Pemerintahan. Gubernur/Bupati/Walikota menerima kekuasaan ini dari Presiden sebagai pengelola keuangan daerah dan mewakili 
pemerintah daerah dalam kepemilikan kekayaan daerah yang dipisahkan.

Pengawasan keuangan daerah merupakan bagian dari pengelolaan keuangan daerah. Pengawasan ini dilaksanakan oleh pihak intern pemerintah seperti Inspektorat Provinsi dan Inspektorat Kabupaten atau Inspektorat Daerah. Inspektorat Daerah bertanggungjawab kepada Bupati melalui Sekretaris Daerah. Salah satu fungsi Inspektorat Daerah adalah melaksanakan pengawasan internal secara berkala dan sewaktu-waktu terhadap kinerja dan keuangan melalui audit, reviu, evaluasi, pemantauan, dan kegiatan pengawasan lainnya. Inspektorat Daerah sebagai Aparat Pengawasan Intern Pemerintah dapat melaksanakan audit kinerja dan audit dengan tujuan tertentu. Inspektorat Daerah tidak melaksanakan audit laporan keuangan. Laporan Hasil Pemeriksaan merupakan pelaporan hasil pelaksanaan tugas tersebut. Kualitas pemeriksaan yang dilakukan oleh Inspektorat Daerah akan tergambar dalam Laporan Hasil Pemeriksaan. Standar pemeriksaan yang digunakan oleh Inspektorat Daerah untuk melaksanakan tugas tersebut adalah Standar Pemeriksaan Keuangan Negara (SPKN,2017). Dengan penerapan SPKN ini diharapkan dapat menghasilkan Laporan Hasil Pemeriksaan (LHP) yang berkualitas. LHP yang berkualitas memiliki unsur tepat waktu, lengkap, akurat, objektif, meyakinkan, jelas dan ringkas (SPKN,2017).

Inspektorat daerah melakukan pengawasan terhadap laporan keuangan pemerintah daerah sebelum diperiksa oleh Badan Pemeriksa Keuangan RI(BPK). BPK RI memberikan opini atas kewajaran laporan keuangan pemerintah daerah yang sebelumnya telah diawasi oleh inspektorat daerah. Berdasarkan hal tersebut maka peran inspektorat daerah dalam meningkatkan opini audit atas laporan keuangan pemerintah daerah sangat signifikan. Dari tahun 2014 sampai 2019, Pemerintah Kabupaten Subang memperoleh opini audit Wajar Tanpa Pengecualian sebanyak 33\% yaitu pada tahun 2018 dan 2019.Salah satu faktor yang mempengaruhi opini laporan keuangan pemerintah daerah yang diberikan oleh BPK RI adalah efektivitas sistem pengendalian intern (SPKN, 2017) . Peran Inspektorat Daerah sebagai Aparat Pengawas Intern Pemerintah sangat diperlukan untuk pencapaian opini Wajar Tanpa Pengecualian (WTP). Perolehan opini selain Wajar Tanpa Pengecualian menunjukkan kinerja yang kurang baik bagi inspektorat daerah. Perolehan opini laporan keuangan daerah selain Wajar Tanpa Pengecualian mencerminkan kualitas pemeriksaan yang dilakukan oleh inspektorat daerah masih harus ditingkatkan.

Laporan Hasil Pemeriksaan yang berkualitas dapat dicapai jika auditor inspektorat daerah bersikap independen (SPKN,2017). Sikap independen merupakan sikap yang tidak memihak siapapun dan tidak dipengaruhi oleh siapapun. Laporan Hasil Pemeriksaan yang berkualitas juga dipengaruhi oleh integritas auditor inspektorat daerah. Skeptisisme profesional dan kompetensi auditor inspektorat daerah juga sangat diperlukan dalam pencapaian Laporan Hasil Pemeriksaan yang berkualitas (SPKN,2017)

Beberapa penelitian yang menjelaskan tentang kualitas hasil pemeriksaan antara lain Sukriah dkk (2009); Badjuri (2012); Queena dan Rohman (2012); Samsi dkk (2012); Nandari dan Latrini (2015); Zarefar dkk (2016); Turangan (2016); dan Riyunti (2017) tapi hasil penelitian tersebut belum konsisten. Penelitian ini meneruskan penelitian Riyunti (2017) dengan menambah variabel budaya. Variabel 
independen yang telah diteliti oleh Riyunti (2017) merupakan faktor-faktor internal auditor yang mempengaruhi kualitas laporan hasil pemeriksaan. Peneliti tertarik untuk menambahkan faktor eksternal yang mempengaruhi kualitas laporan hasil pemeriksaan diantaranya adalah budaya. Pengaruh nilai budaya terhadap nilai akuntansi sudah diteliti oleh Ramadhan (2012). Pengaruh budaya terhadap efektivitas organisasi telah diteliti oleh Armia (2002). Hubungan budaya dengan persepsi penggunaan dan kepatuhan terhadap standar audit internal juga telah diteliti oleh Abdolmohammadi dan Sarens (2009). Objek penelitian ini yaitu Inspektorat Daerah Kabupaten Subang. Berdasarkan uraian di atas, penulis tertarik untuk melakukan penelitian dengan judul "Independensi, Integritas, Skeptisisme Profesional, Budaya, Kompetensi dan Kualitas Laporan Hasil Pemeriksaan".

Tujuan penelitian ini untuk mengetahui apakah independensi, integritas, skeptisisme profesional, budaya dan kompetensi berpengaruh terhadap kualitas laporan hasil pemeriksaan Inspektorat Daerah Kabupaten Subang baik secara parsial maupun simultan.

\section{KERANGKA TEORITIS DAN PENGEMBANGAN HIPOTESIS}

Teori Stewardship mempunyai akar psikologi dan sosiologi yang didesain untuk menjelaskan situasi dimana manajer sebagai steward dan bertindak sesuai kepentingan pemilik (Donaldson \&Davis, 1989, 1991). Steward merasa kepentingan bersama dan berperilaku sesuai dengan perilaku pemilik merupakan pertimbangan yang rasional karena steward lebih melihat pada usaha untuk mencapai tujuan organisasi (Eko Raharjo, 2007). Implementasinya dalam penelitian ini adalah Inspektorat Daerah sebagai steward akan melaksanakan pelayanan kepada masyarakat dengan sebaikbaiknya sehingga good government governance dapat tercapai.

Menurut Fritz Heider, teori atribusi merupakan teori yang menjelaskan tentang perilaku seseorang. Teori atribusi menjelaskan mengenai proses bagaimana kita menentukan penyebab perilaku seseorang (Queena, 2012:10). Penelitian ini menggunakan teori atribusi karena peneliti melakukan studi empiris mengenai faktor-faktor yang mempengaruhi kualitas laporan hasil pemeriksaan yang disusun oleh inspektorat daerah. Kualitas laporan hasil pemeriksaan pada dasarnya dipengaruhi oleh factor internal dan eksternal pemeriksa itu sendiri.

Peraturan BPK RI Nomor 1 Tahun 2017 Tentang Standar Pemeriksaan Keuangan Negara Pasal 1 ayat (8) menyebutkan bahwa pemeriksaan adalah proses identifikasi masalah, analisis, dan evaluasi yang dilakukan secara independen, objektif, dan profesional berdasarkan standar pemeriksaan, untuk menilai kebenaran, kecermatan, kredibilitas, dan keandalan informasi mengenai pengelolaan dan tanggung jawab keuangan negara.

Standar Pemeriksaan Keuangan Nl.egara (SPKN) melalui peraturan BPKRI Nomor 1 Tahun 2017 menyebutkan bahwa laporan hasil pemeriksaan adalah "laporan tertulis dari proses pemeriksaan yang berisi hasil analisis atas pengujian bukti yang diperoleh saat pelaksanaan pemeriksaan.....Pemeriksa harus menyusun LHP secara tepat waktu, lengkap, akurat, objektif,meyakinkan, jelas, dan ringkas".

$$
\text { Kualitas Laporan Hasil }
$$

Pemeriksaan berdasarkan referensi dari PSP 300 par. 7 dan Materi Penerapan dan Penjelasan Lain par A1 sampai dengan A7. Kerangka Konseptual Pemeriksaan SPKN 2017 paragraf 45 menyebutkan 
bahwa "Independensi adalah suatu sikap dan tindakan dalam melaksanakan Pemeriksaan untuk tidak memihak kepada siapapun dan tidak dipengaruhi oleh siapapun. Pemeriksa harus objektif dan bebas dari benturan kepentingan (conflict of interest) dalam melaksanakan tanggung jawab profesionalnya. Pemeriksa juga harus bertanggung jawab untuk terus-menerus mempertahankan independensi dalam pemikiran (independence of mind) dan independensi dalam penampilan (independence in appearance)". Kerangka Konseptual Pemeriksaan SPKN 2017 paragraf 46 menyebutkan bahwa "Integritas merupakan mutu, sifat, atau keadaan yang menunjukkan kesatuan yang utuh, dimilikinya sifat jujur, kerja keras, serta kompetensi yang memadai".

Standar Pemeriksaan Keuangan Negara (SPKN) melalui peraturan BPK-RI Nomor 1 Tahun 2017 mendefinisikan Skeptisisme Profesional adalah : "sikap yang mencakup pikiran yang selalu mempertanyakan dan melakukan evaluasi secara kritis terhadap bukti pemeriksaan atau hal-hal lain selama pemeriksaan."

Hofstede (2001) mendefinisikan budaya sebagai berikut : "The collective programming of the mind that distinguishes the members of one group or category of people from another."

Program mental tersebut berpola pikiran (thinking), perasaan (feeling), dan tindakan (action) atau disebut dengan "software of the mind" (Armia, 2002). Hofstede (2001) membagi budaya menjadi empat dimensi sebagai berikut:

a. The power distance between a boss $B$ and a subordinate $S$ in a hierarchy is the difference between the extent to which $B$ can determine the behavior of $S$ and the extent to which $S$ can determine the behavior of $B$. Power Distance atau jarak kekuasaan dimana anggota dari suatu organisasi atau lembaga yang berada dalam posisi yang kurang kuat menerima dan berharap kekuasaan didistribusikan secara tidak merata.

b. Dimensi 'uncertainty avoidance' dijelaskan oleh Hofstede (2001) sebagai berikut:

Uncertainty about the future is a basic fact of human life with which we try to cope throuhj the domains of technology, law, and religion. In organizationas these take the form of technology, rules, and rituals. Uncertainty avoidance should not be confused with risk avoidance.

c. Hofstede (2001) menjelaskan dimensi individualism sebagai sisi yang berlawanan dari collectivism sebagai berikut:

"It describes the relationship between the individual and the collectivity that prevails in a given society. It is reflected in the way people live together-for example, in nuclear famiies, or tribes - and it has many implications for values and behavior."

d. Hofstede

menjelaskan masculinity dan feminimi ty sebagai berikut:

The dominant gender role patterns in the vast majority of both traditional and modern societies. (I will use 'sex' when referring to biological functions and 'gender' when referring to social functions).

Menurut Standar Pemeriksaan Keuangan Negara (SPKN) melalui peraturan BPK-RI Nomor 1 Tahun 2017 : "Kompetensi adalah pendidikan, pengalaman dan/atau keahlian yang dimiliki seseorang, baik tentang pemeriksaan maupun tentang hal-hal atau bidang tertentu.

\section{HIPOTESIS}

Hipotesis yang dirumuskan dalam penelitian ini sebagai berikut:

$\mathbf{H}_{1}$ : Independensi berpengaruh terhadap Kualitas Laporan Hasil Pemeriksaan 
$\mathbf{H}_{2}$ : Integritas berpengaruh terhadap Kualitas Laporan Hasil Pemeriksaan

$\mathbf{H}_{3}$ : Skeptisisme Profesional berpengaruh terhadap Kualitas Laporan Hasil Pemeriksaan

$\mathbf{H}_{4}$ : Budaya berpengaruh terhadap Kualitas Laporan Hasil Pemeriksaan

$\mathbf{H}_{5}$ : Kompetensi berpengaruh terhadap Kualitas Laporan Hasil Pemeriksaan

$\mathbf{H}_{6}$ : Independensi, Integritas, Skeptisisme Profesional, Budaya dan Kompetensi berpengaruh terhadap Kualitas Laporan Hasil Pemeriksaan

\section{METODOLOGI PENELITIAN}

Penelitian ini merupakan penelitian kuantitatif. Metode yang digunakan dalam penelitian ini adalah statistik deskriptif. Sumber data yang digunakan dalam penelitian ini adalah sumber primer dan sumber sekunder. Alat analisis yang digunakan dalam penelitian ini adalah Microsoft Excel dan SmartPLS 3. Teknik pemilihan sampel yang digunakan adalah teknik nonprobability sampling sehingga sampel yang digunakan dalam penelitian ini adalah seluruh pegawai Inspektorat Daerah Kabupaten Subang yang berjumlah 61 orang

\section{HASIL DAN PEMBAHASAN}

Terdapat dua karakteristik responden yang dimasukkan dalam penelitian ini, yaitu jenis kelamin dan pendidikan terakhir. Data mengenai jenis kelamin responden dikelompokkan menjadi dua yaitu, pria sebanyak 37 responden dan wanita sebanyak 24 responden. Data mengenai pendidikan terakhir responden dikelompokkan menjadi lima, yaitu reponden yang telah menempun pendidikan SMA/Sederajat sebanyak 15 responden, Diploma (D3) sebanyak 4 responden, Sarjana (S1) sebanyak 29 responden, Pasca Sarjana (S2) sebanyak 13 responden

\section{Variabel Independensi}

Bobot masing-masing indikator
dalam merefleksikan
independensiabel
berikut ini.

Tabel 1

Bobot Faktor Variabel Independensi

\begin{tabular}{|c|c|c|c|c|}
\hline Indikator & $\begin{array}{c}\text { Pern } \\
\text { yata } \\
\text { an }\end{array}$ & $\begin{array}{l}\text { Loadi } \\
\text { ng } \\
\text { Facto } \\
r\end{array}$ & $\begin{array}{c}\text { Measurement } \\
\text { Model }\end{array}$ & $\mathbf{T}_{\text {hitung }}$ \\
\hline \multirow{3}{*}{$\begin{array}{c}\text { Objektif dan } \\
\text { bebas dari } \\
\text { benturan } \\
\text { kepentingan }\end{array}$} & $\begin{array}{c}\text { X1.1 } \\
.1\end{array}$ & 0,837 & $\begin{array}{c}\mathrm{IP}=0,837 \mathrm{X}_{1}+0 \\
, 188\end{array}$ & 4,459 \\
\hline & $\begin{array}{c}\mathrm{X} 1.1 \\
.2\end{array}$ & 0,675 & $\begin{array}{c}\mathrm{IP}=0,675 \mathrm{X}_{1}+0 \\
, 237\end{array}$ & 2,849 \\
\hline & $\begin{array}{c}\mathrm{X} 1.1 \\
.3\end{array}$ & 0,834 & $\begin{array}{c}\mathrm{IP}=0,834 \mathrm{X}_{1}+0 \\
, 213\end{array}$ & 3,920 \\
\hline \multirow{3}{*}{$\begin{array}{c}\text { Indepedensi } \\
\text { dalam } \\
\text { Pemikiran }\end{array}$} & $\begin{array}{c}\mathrm{X} 1.2 \\
.1\end{array}$ & 0,893 & $\begin{array}{c}\mathrm{IP}=0,893 \mathrm{X}_{1}+0 \\
, 186\end{array}$ & 4,802 \\
\hline & $\begin{array}{c}\mathrm{X} 1.2 \\
.2\end{array}$ & 0,884 & $\begin{array}{c}\mathrm{IP}=0,884 \mathrm{X}_{1}+0 \\
, 146\end{array}$ & 6,058 \\
\hline & $\begin{array}{c}\mathrm{X} 1.2 \\
.3\end{array}$ & 0,826 & $\begin{array}{c}\mathrm{IP}=0,826 \mathrm{X}_{1}+0 \\
, 189\end{array}$ & 4,359 \\
\hline \multirow{3}{*}{$\begin{array}{c}\text { Independensi } \\
\text { dalam } \\
\text { Penampilan }\end{array}$} & $\begin{array}{c}\mathrm{X} 1.3 \\
.1\end{array}$ & 0,870 & $\begin{array}{c}\mathrm{IP}=0,870 \mathrm{X}_{1}+0 \\
, 205\end{array}$ & 4,242 \\
\hline & $\begin{array}{c}\mathrm{X} 1.3 \\
.2\end{array}$ & 0,846 & $\begin{array}{c}\mathrm{IP}=0,846 \mathrm{X}_{1}+0 \\
, 083\end{array}$ & 10,179 \\
\hline & $\begin{array}{c}\mathrm{X} 1.3 \\
.3\end{array}$ & 0,706 & $\begin{array}{c}\mathrm{IP}=0,706 \mathrm{X}_{1}+0 \\
, 153\end{array}$ & 4,600 \\
\hline \multicolumn{5}{|c|}{ Composite Reliability $(\mathrm{CR})=0,949$} \\
\hline Average Va & $x t$ & 18 & 0,676 & \\
\hline
\end{tabular}

Sumber: Data primer yang diolah (2019).

\section{Variabel Integritas}

Bobot masing-masing indikator dalam merefleksikan variabel integritas terdapat dalam tabel 2 berikut ini.

Tabel 2

Bobot Faktor Variabel Integritas

\begin{tabular}{|c|c|c|c|c|}
\hline \multirow{2}{*}{$\begin{array}{c}\text { Indikato } \\
\mathbf{r}\end{array}$} & $\begin{array}{c}\text { Pernyata } \\
\text { an }\end{array}$ & $\begin{array}{c}\text { Loadi } \\
\boldsymbol{n g} \\
\text { Facto } \\
\boldsymbol{r}\end{array}$ & $\begin{array}{c}\text { Measurement } \\
\text { Model }\end{array}$ & $\begin{array}{c}\mathbf{T}_{\text {hitun }} \\
\mathbf{g}\end{array}$ \\
\hline \multirow{4}{*}{$\begin{array}{c}\text { Kejujura } \\
\mathrm{n}\end{array}$} & $\mathrm{X} 2.1 .1$ & 0,811 & $\begin{array}{c}\mathrm{IG}=0,811 \mathrm{X}_{2}+0 \\
, 224\end{array}$ & $\begin{array}{c}3,61 \\
3\end{array}$ \\
\cline { 2 - 5 } & $\mathrm{X} 2.1 .2$ & 0,830 & $\begin{array}{c}\mathrm{IG}=0,830 \mathrm{X}_{2}+0 \\
, 198\end{array}$ & $\begin{array}{c}4,18 \\
5\end{array}$ \\
\cline { 2 - 5 } & $\mathrm{X} 2.1 .3$ & 0,938 & $\begin{array}{c}\mathrm{IG}=0,938 \mathrm{X}_{2}+0 \\
, 087\end{array}$ & $\begin{array}{c}10,8 \\
13\end{array}$ \\
\hline \multirow{3}{*}{$\begin{array}{c}\text { Keberani } \\
\text { an }\end{array}$} & $\mathrm{X} 2.2 .1$ & 0,733 & $\begin{array}{c}\mathrm{IG}=0,733 \mathrm{X}_{2}+0 \\
, 206\end{array}$ & $\begin{array}{c}3,56 \\
2\end{array}$ \\
\cline { 2 - 5 } & $\mathrm{X} 2.2 .2$ & 0,846 & $\mathrm{IG}=0,846 \mathrm{X}_{2}+0$ & 6,18 \\
& & & 137 & 0 \\
\hline
\end{tabular}




\begin{tabular}{|c|c|c|c|c|}
\hline \multirow[t]{2}{*}{$\begin{array}{l}\text { Indikato } \\
\mathbf{r}\end{array}$} & $\begin{array}{c}\text { Pernyata } \\
\text { an }\end{array}$ & $\begin{array}{c}\text { Loadi } \\
\text { ng } \\
\text { Facto }\end{array}$ & $\begin{array}{c}\text { Measurement } \\
\text { Model }\end{array}$ & $\begin{array}{c}\mathbf{T}_{\text {hitun }} \\
\mathrm{g}\end{array}$ \\
\hline & $\mathrm{X} 2.2 .3$ & 0,969 & $\begin{array}{c}\mathrm{IG}=0,969 \mathrm{X}_{2}+0 \\
, 085\end{array}$ & $\begin{array}{c}11,3 \\
76\end{array}$ \\
\hline \multirow{3}{*}{$\begin{array}{c}\text { Sikap } \\
\text { bijaksan } \\
\text { a }\end{array}$} & $\mathrm{X} 2.3 .1$ & 0,877 & $\begin{array}{c}\mathrm{IG}=0,877 \mathrm{X}_{2}+0 \\
, 076\end{array}$ & $\begin{array}{c}11,5 \\
96\end{array}$ \\
\hline & $\mathrm{X} 2.3 .2$ & 0,763 & $\begin{array}{c}\mathrm{IG}=0,761 \mathrm{X}_{2}+0 \\
, 169\end{array}$ & $\begin{array}{c}4,50 \\
8\end{array}$ \\
\hline & $\mathrm{X} 2.3 .3$ & 0,917 & $\begin{array}{c}\mathrm{IG}=0,917 \mathrm{X}_{2}+0 \\
, 108\end{array}$ & $\begin{array}{c}8,47 \\
9 \\
\end{array}$ \\
\hline \multirow{3}{*}{$\begin{array}{l}\text { Tanggun } \\
\text { g jawab }\end{array}$} & $\mathrm{X} 2.4 .1$ & 0,756 & $\begin{array}{c}\mathrm{IG}=0,756 \mathrm{X}_{2}+0 \\
, 216\end{array}$ & $\begin{array}{c}3,50 \\
2\end{array}$ \\
\hline & $\mathrm{X} 2.4 .2$ & 0,902 & $\begin{array}{c}\mathrm{IG}=0,902 \mathrm{X}_{2}+0 \\
, 100\end{array}$ & $\begin{array}{c}9,00 \\
8\end{array}$ \\
\hline & $\mathrm{X} 2.4 .3$ & 0,956 & $\begin{array}{c}\mathrm{IG}=0,956 \mathrm{X}_{2}+0 \\
, 088\end{array}$ & $\begin{array}{c}10,8 \\
09\end{array}$ \\
\hline Composit & eliability & )$=0$ & & \\
\hline
\end{tabular}

Sumber: Data primer yang diolah (2019).

\section{Variabel Skeptisisme Profesional}

Bobot masing-masing indikator dalam merefleksikan variabel skeptisisme profesional terdapat dalam tabel 4 berikut ini.

Tabel 3

\begin{tabular}{|c|c|c|c|c|}
\hline Bobot $\mathrm{F}$ & $\begin{array}{l}\text { or } \\
\text { Prc }\end{array}$ & abe & epti & \\
\hline Indikator & $\begin{array}{c}\begin{array}{c}\text { Pern } \\
\text { yata } \\
\text { an }\end{array} \\
\end{array}$ & $\begin{array}{c}\text { Loading } \\
\text { Factor }\end{array}$ & $\begin{array}{c}\text { Measure } \\
\text { ment } \\
\text { Model }\end{array}$ & $\begin{array}{c}\mathbf{T}_{\text {hitu }} \\
\mathrm{ng}\end{array}$ \\
\hline $\begin{array}{c}\text { Bukti } \\
\text { pemeriksaan } \\
\text { yang } \\
\text { bertentangan } \\
\text { dengan bukti } \\
\text { pemeriksaan } \\
\text { lain yang } \\
\text { diperoleh }\end{array}$ & X3.1 & 0,821 & $\begin{array}{l}\mathrm{SP}=0,821 \\
\mathrm{Y}_{1}+0,084\end{array}$ & $\begin{array}{c}9,82 \\
0\end{array}$ \\
\hline $\begin{array}{l}\text { Informasi yang } \\
\text { menimbulkan } \\
\text { pertanyaan } \\
\text { tentang } \\
\text { keandalan } \\
\text { dokumen dan } \\
\text { tanggapan } \\
\text { terhadap } \\
\text { permintaan } \\
\text { keterangan yang } \\
\text { digunakan } \\
\text { sebagai bukti } \\
\text { pemeriksaan }\end{array}$ & X3.2 & 0,942 & $\begin{array}{l}\mathrm{SP}=0,942 \\
\mathrm{Y}_{1}+0,032\end{array}$ & $\begin{array}{c}29,0 \\
72\end{array}$ \\
\hline $\begin{array}{l}\text { Keadaan yang } \\
\text { mengindikasi } \\
\text { adanya }\end{array}$ & X3.3 & 0,840 & $\begin{array}{l}\mathrm{SP}=0,840 \\
\mathrm{Y}_{1}+0,069\end{array}$ & $\begin{array}{c}12,2 \\
36\end{array}$ \\
\hline
\end{tabular}

\begin{tabular}{|c|c|c|c|c|}
\hline Indikator & $\begin{array}{c}\text { Pern } \\
\text { yata } \\
\text { an }\end{array}$ & $\begin{array}{c}\text { Loading } \\
\text { Factor }\end{array}$ & $\begin{array}{c}\text { Measure } \\
\text { ment } \\
\text { Model }\end{array}$ & $\begin{array}{c}\mathbf{T}_{\text {hitu }} \\
\mathbf{n g}\end{array}$ \\
\hline $\begin{array}{c}\text { kecurangan } \\
\text { dan/atau } \\
\text { ketidakpatuhan }\end{array}$ & & & & \\
\hline $\begin{array}{c}\text { Kondisi yang } \\
\text { memungkinkan } \\
\text { perlunya } \\
\text { prosedur } \\
\text { pemeriksaan } \\
\text { tambahan selain } \\
\text { prosedur yang } \\
\text { di persyaratkan } \\
\text { dalam pedoman } \\
\text { pemeriksaan }\end{array}$ & $\mathrm{X} 3.4$ & 0,956 & $\begin{array}{l}\mathrm{SP}=0,956 \\
\mathrm{Y}_{1}+0,019\end{array}$ & $\begin{array}{c}51,5 \\
49\end{array}$ \\
\hline \multicolumn{5}{|c|}{ Composite Reliability $(\mathrm{CR})=0,939$} \\
\hline
\end{tabular}

Sumber: Data primer yang diolah (2019).

\section{Variabel Budaya}

Bobot masing-masing indikator dalam merefleksikan variabel budaya terdapat dalam tabel 4 berikut ini.

Tabel 4

Bobot Faktor Variabel Budaya

\begin{tabular}{|c|c|c|c|c|}
\hline Indikator & $\begin{array}{c}\text { Pernyat } \\
\text { aan }\end{array}$ & $\begin{array}{c}\text { Loadi } \\
\text { Facto } \\
\boldsymbol{r}\end{array}$ & $\begin{array}{c}\text { Measurement } \\
\text { Model }\end{array}$ & $\begin{array}{c}\mathbf{T}_{\text {hitu }} \\
\mathbf{n g}\end{array}$ \\
\hline $\begin{array}{c}\text { Struktur } \\
\text { hirarki }\end{array}$ & $\mathrm{X} 4.1$ & 0,683 & $\begin{array}{c}\mathrm{BD}=0,683 \mathrm{Y}_{1}+ \\
0,331\end{array}$ & $\begin{array}{c}2,06 \\
5\end{array}$ \\
\hline $\begin{array}{c}\text { Penghinda } \\
\text { ran } \\
\text { terhadap } \\
\text { ketidakpas } \\
\text { tian }\end{array}$ & $\mathrm{X} 4.2$ & 0,891 & $\begin{array}{c}\mathrm{BD}=0,891 \mathrm{Y}_{1}+ \\
0,211\end{array}$ & $\begin{array}{c}4,22 \\
2\end{array}$ \\
\hline $\begin{array}{c}\text { Kolektivit } \\
\text { as }\end{array}$ & $\mathrm{X} 4.3$ & 0,495 & $\begin{array}{c}\mathrm{BD}=0,495 \mathrm{Y}_{1}+ \\
0,295\end{array}$ & $\begin{array}{c}1,67 \\
5\end{array}$ \\
\hline $\begin{array}{c}\text { Maskulinit } \\
\text { as vs } \\
\text { femininita } \\
\mathrm{s}\end{array}$ & $\mathrm{X} 4.4$ & 0,777 & $\mathrm{BD}=0,777 \mathrm{Y}_{1}+$ & 3,82 \\
0,203 & 8 \\
\hline \multicolumn{4}{c|}{} & \multicolumn{2}{|c|}{} \\
\hline Average Variance Extracted $(\mathrm{AVE})=0,527$ \\
\hline
\end{tabular}

Sumber: Data primer yang diolah (2019).

\section{Variabel Kompetensi}

Bobot masing-masing indikator dalam merefleksikan variabel kompetensi terdapat dalam tabel 5 berikut ini.

Tabel 5

Bobot Faktor Variabel Kompetensi 


\begin{tabular}{|c|c|c|c|c|}
\hline Indikator & $\begin{array}{c}\text { Pernyat } \\
\text { aan }\end{array}$ & $\begin{array}{c}\text { Loadi } \\
\text { ng } \\
\text { Facto } \\
r\end{array}$ & $\begin{array}{c}\text { Measurement } \\
\text { Model }\end{array}$ & $\begin{array}{c}\mathbf{T}_{\text {hitun }} \\
\mathrm{g}\end{array}$ \\
\hline \multirow{3}{*}{$\begin{array}{c}\text { Latar } \\
\text { belakang } \\
\text { pendidika } \\
\mathrm{n}\end{array}$} & X5.1.1 & 0,699 & $\begin{array}{c}\mathrm{KP}=0,699 \mathrm{X}_{3}+ \\
0,110\end{array}$ & $\begin{array}{c}6,35 \\
0\end{array}$ \\
\hline & $\mathrm{X} 5.1 .2$ & 0,936 & $\begin{array}{c}\mathrm{KP}=0,936 \mathrm{X}_{3}+ \\
0,029\end{array}$ & $\begin{array}{c}31,8 \\
69\end{array}$ \\
\hline & $\mathrm{X} 5.1 .3$ & 0,703 & $\begin{array}{c}\mathrm{KP}=0,703 \mathrm{X}_{3}+ \\
0,084\end{array}$ & $\begin{array}{c}8,40 \\
9\end{array}$ \\
\hline \multirow{3}{*}{ Keahlian } & X5.2.1 & 0,761 & $\begin{array}{c}\mathrm{KP}=0,761 \mathrm{X}_{3}+ \\
0,091\end{array}$ & $\begin{array}{c}8,39 \\
9\end{array}$ \\
\hline & $\mathrm{X} 5.2 .2$ & 0,925 & $\begin{array}{c}\mathrm{KP}=0,925 \mathrm{X}_{3}+ \\
0,018\end{array}$ & $\begin{array}{c}50,6 \\
94\end{array}$ \\
\hline & $\mathrm{X} 5.2 .3$ & 0,835 & $\begin{array}{c}\mathrm{KP}=0,835 \mathrm{X}_{3}+ \\
0,045\end{array}$ & $\begin{array}{c}18,4 \\
15\end{array}$ \\
\hline \multirow{3}{*}{$\begin{array}{l}\text { Pengalam } \\
\text { an }\end{array}$} & X5.3.1 & 0,770 & $\begin{array}{c}\mathrm{KP}=0,770 \mathrm{X}_{3}+ \\
0,099\end{array}$ & $\begin{array}{c}7,82 \\
0\end{array}$ \\
\hline & $\mathrm{X} 5.3 .2$ & 0,720 & $\begin{array}{c}\mathrm{KP}=0,720 \mathrm{X}_{3}+ \\
0,087\end{array}$ & $\begin{array}{c}8,22 \\
9\end{array}$ \\
\hline & $\mathrm{X} 5.3 .3$ & 0,690 & $\begin{array}{c}\mathrm{KP}=0,690 \mathrm{X}_{3}+ \\
0,113\end{array}$ & $\begin{array}{c}6,09 \\
9\end{array}$ \\
\hline $\begin{array}{l}\text { Pengetahu } \\
\text { an umum } \\
\text { tentang } \\
\text { pemerinta } \\
\text { han }\end{array}$ & X5.4 & 0,852 & $\begin{array}{c}\mathrm{KP}=0,852 \mathrm{X}_{3}+ \\
0,058\end{array}$ & $\begin{array}{c}14,7 \\
23\end{array}$ \\
\hline \multirow{3}{*}{$\begin{array}{c}\text { Keahlian } \\
\text { khusus }\end{array}$} & X5.5.1 & 0,905 & $\begin{array}{c}\mathrm{KP}=0,905 \mathrm{X}_{3}+ \\
0,061\end{array}$ & $\begin{array}{c}14,7 \\
27\end{array}$ \\
\hline & $\mathrm{X} 5.5 .2$ & 0,620 & $\begin{array}{c}\mathrm{KP}=0,620 \mathrm{X}_{3}+ \\
0,112\end{array}$ & $\begin{array}{c}5,51 \\
9\end{array}$ \\
\hline & $\mathrm{X} 5.5 .3$ & 0,892 & $\begin{array}{c}\mathrm{KP}=0,892 \mathrm{X}_{3}+ \\
0,066\end{array}$ & $\begin{array}{c}13,5 \\
07\end{array}$ \\
\hline \multicolumn{5}{|c|}{ Composite Reliability $(\mathrm{CR})=0,958$} \\
\hline Aver & ce Ex & (A & 39 & \\
\hline
\end{tabular}

Sumber: Data primer yang diolah (2019).

\section{Variabel Kualitas Laporan Hasi Pemeriksaan}

Bobot masing-masing indikator dalam merefleksikan variabel kualitas laporan hasil pemeriksaan terdapat dalam tabel 6 berikut ini.

\section{Tabel 6}

\section{Bobot Faktor Variabel Kualitas} Laporan Hasil Pemeriksaan

\begin{tabular}{|c|c|c|c|c|}
\hline $\begin{array}{c}\text { Indikato } \\
\mathbf{r}\end{array}$ & $\begin{array}{c}\text { Pernyat } \\
\text { aan }\end{array}$ & $\begin{array}{c}\text { Loadi } \\
\boldsymbol{n g} \\
\text { Facto } \\
\boldsymbol{r}\end{array}$ & $\begin{array}{c}\text { Measurement } \\
\text { Model }\end{array}$ & $\begin{array}{c}\mathbf{T}_{\text {hitu }} \\
\mathbf{n g}\end{array}$ \\
\hline $\begin{array}{c}\text { Tepat } \\
\text { waktu }\end{array}$ & $\mathrm{Y} .1$ & 0,754 & $\begin{array}{c}\mathrm{KLHP}=0,754 \mathrm{Y}+ \\
0,047\end{array}$ & $\begin{array}{c}15,8 \\
79\end{array}$ \\
\hline \multirow{2}{*}{ Lengkap } & $\mathrm{Y} .2 .1$ & 0,832 & $\begin{array}{c}\mathrm{KLHP}=0,832 \mathrm{Y}+ \\
0,045\end{array}$ & $\begin{array}{c}18,5 \\
97\end{array}$ \\
\cline { 2 - 5 } & $\mathrm{Y} .2 .2$ & 0,818 & $\begin{array}{c}\mathrm{KLHP}=0,818 \mathrm{Y}+ \\
0,044\end{array}$ & $\begin{array}{c}18,5 \\
80\end{array}$ \\
\hline
\end{tabular}

\begin{tabular}{|c|c|c|c|c|}
\hline $\begin{array}{c}\text { Indikato } \\
\mathbf{r}\end{array}$ & $\begin{array}{c}\text { Pernyat } \\
\text { aan }\end{array}$ & $\begin{array}{c}\text { Loadi } \\
\text { ng } \\
\text { Facto } \\
r\end{array}$ & $\begin{array}{c}\text { Measurement } \\
\text { Model }\end{array}$ & $\begin{array}{c}\mathbf{T}_{\text {hitu }} \\
\text { ng }\end{array}$ \\
\hline Akurat & Y.3 & 0,741 & $\begin{array}{c}\text { KLHP }=0,741 \mathrm{Y}+ \\
0,059\end{array}$ & $\begin{array}{c}12,5 \\
31\end{array}$ \\
\hline \multirow{2}{*}{ Objektif } & Y.4.1 & 0,516 & $\begin{array}{c}\text { KLHP }=0,516 \mathrm{Y}+ \\
0,207\end{array}$ & $\begin{array}{c}2,49 \\
4\end{array}$ \\
\hline & Y.4.2 & 0,866 & $\begin{array}{c}\text { KLHP }=0,866 \mathrm{Y}+ \\
0,054\end{array}$ & $\begin{array}{c}15,9 \\
26\end{array}$ \\
\hline $\begin{array}{c}\text { Meyakin } \\
\text { kan }\end{array}$ & Y.5 & 0,725 & $\begin{array}{c}\text { KLHP }=0,725 \mathrm{Y}+ \\
0,079\end{array}$ & $\begin{array}{c}9,19 \\
4\end{array}$ \\
\hline \multirow{2}{*}{ Jelas } & Y.6.1 & 0,729 & $\begin{array}{c}\text { KLHP }=0,729 \mathrm{Y}+ \\
0,088\end{array}$ & $\begin{array}{c}8,25 \\
3\end{array}$ \\
\hline & Y.6.2 & 0,613 & $\begin{array}{c}\text { KLHP }=0,613 \mathrm{Y}+ \\
0,164\end{array}$ & $\begin{array}{c}3,73 \\
8\end{array}$ \\
\hline Ringkas & Y.7 & 0,704 & $\begin{array}{c}\text { KLHP }=0,704 Y+ \\
0,150\end{array}$ & $\begin{array}{c}4,69 \\
5\end{array}$ \\
\hline \multicolumn{5}{|c|}{ Composite Reliability $(\mathrm{CR})=0,921$} \\
\hline Average 1 & ance Ext & ed (A & $=0,542$ & \\
\hline
\end{tabular}

Sumber: Data primer yang diolah (2019).

Tabel 7

Nilai Koefisien Korelasi

\begin{tabular}{|l|c|c|}
\hline \multicolumn{1}{|c|}{ Variabel Laten } & $\begin{array}{c}\text { Koefisien } \\
\text { Korelasi }\end{array}$ & Keterangan \\
\hline $\begin{array}{l}\text { Indepedensi > Kualitas Laporan } \\
\text { Hasil Pemeriksaan }\end{array}$ & 0,211 & Rendah \\
\hline $\begin{array}{l}\text { Integritas > Kualitas Laporan } \\
\text { Hasil Pemeriksaan }\end{array}$ & 0,322 & Rendah \\
\hline $\begin{array}{l}\text { Skeptisisme Profesional > } \\
\text { Kualitas Laporan Hasil } \\
\text { Pemeriksaan }\end{array}$ & 0,252 & Rendah \\
\hline $\begin{array}{l}\text { Budaya > Kualitas Laporan } \\
\text { Hasil Pemeriksaan }\end{array}$ & $-0,002$ & $\begin{array}{c}\text { Sangat } \\
\text { Rendah }\end{array}$ \\
\hline $\begin{array}{l}\text { Kompetensi > Kualitas Laporan } \\
\text { Hasil Pemeriksaan }\end{array}$ & 0,371 & Rendah \\
\hline
\end{tabular}

Sumber: Data primer yang diolah (2019) dan (Noviana, 2015).

Nilai koefisien determinasi ( $R$ Square / $R^{2}$ ) menunjukkan besarnya ketepatan pengaruh antar variabel laten. Hasil uji nilai koefisien korelasi dalam tabel 8 berikut ini:

Tabel 8

Nilai $\mathbf{R}$ Square $\left(\mathbf{R}^{2}\right)$

\begin{tabular}{|l|c|c|}
\hline \multicolumn{1}{|c|}{ Variabel Laten } & $\begin{array}{c}\text { Koefisie } \\
\mathbf{n} \\
\text { Korelasi }\end{array}$ & $\begin{array}{c}\text { Keteranga } \\
\mathbf{n}\end{array}$ \\
\hline $\begin{array}{l}\text { Kualitas Laporan } \\
\text { Hasil Pemeriksaan }\end{array}$ & 0.521 & Moderate \\
\hline
\end{tabular}


Berdasarkan tabel 4.10 maka hasil uji $\mathrm{R}^{2}$ dalam penelitian ini yaitu nilai koefieisen determinasi $\left(R^{2}\right)$ kualitas laporan hasil pemeriksaan besar 0.521 dan termasuk kedalam kriteria determinasi moderate (Noviana, 2015). Hasil ini menunjukkan bahwa $52,1 \%$ variabel kualitas laporan hasil pemeriksaan dapat dipengaruhi oleh variabel independensi, integritas, skeptisisme professional, budaya dan kompetensi. Sedangkan sisanya sebesar $47,9 \%$ dipengaruhi oleh variabel lain yang tidak diteliti dalam penelitian ini.

\section{Analisis Pengujian Hipotesis}

\section{Pengaruh Independensi Terhadap} Kualitas Laporan Hasil Pemeriksaan

Dari hasil menggunakan Software SmartPLS maka diperoleh persamaan struktural sebagai berikut:

Tabel 9

Persamaan Struktural Independensi Terhadap Kualitas Laporan Hasil Pemeriksaan

\begin{tabular}{|c|c|c|c|c|}
\hline $\begin{array}{c}\text { Endogenou } \\
\text { s Construct } \\
\text { Kualitas } \\
\text { Laporan } \\
\text { Hasil } \\
\text { Pemeriksaa } \\
\text { n }\end{array}$ & $=$ & $\begin{array}{c}\text { Eksogenou } \\
\text { s Construct } \\
\text { Independen } \\
\text { si }\end{array}$ & + & $\begin{array}{c}\text { Error } \\
\text { Varianc } \\
e\end{array}$ \\
\hline$\eta$ & $=$ & $\begin{array}{r}0,211 \\
2,218^{*}\end{array}$ & + & 0,095 \\
\hline
\end{tabular}

* Nilai t statistik uji-t

Sumber: Data primer yang diolah (2019).

Tabel 9 menunjukkan bahwa koefisien pengaruh independensi terhadap kualitas laporan hasil pemeriksaan sebesar 0,211 atau $21,1 \%$ sedangkan sisanya $78,9 \%$ merupakan pengaruh faktor-faktor lain diluar variabel eksogen yang diteliti.

Berdasarkan hasil pengujian, nilai $t_{\text {hitung }}$ korelasi independensi sebesar 2,218 lebih besar dari tabel $(1,67303)$ sehingga $H_{1}$ diterima. Jadi berdasarkan hasil pengujian dapat disimpulkan bahwa independensi berpengaruh terhadap kualitas laporan hasil pemeriksaan.

\section{Pengaruh Integritas Terhadap Kualitas Laporan Hasil Pemeriksaan}

Dari hasil menggunakan Software SmartPLS maka diperoleh persamaan struktural sebagai berikut:

Tabel 10

Persamaan Struktural Integritas Terhadap Kualitas Laporan Hasil Pemeriksaan

\begin{tabular}{cccc}
\hline $\begin{array}{c}\text { Endogenou } \\
\boldsymbol{s} \text { Construct } \\
\text { Kualitas } \\
\text { Laporan } \\
\text { Hasil } \\
\begin{array}{c}\text { Pemeriksaa } \\
\mathbf{n}\end{array}\end{array}$ & $=\begin{array}{c}\text { Eksogenou } \\
\boldsymbol{s} \\
\text { Construct } \\
\text { Integritas }\end{array}$ & $+\begin{array}{c}\text { Error } \\
\text { Varianc } \\
\boldsymbol{n}\end{array}$ \\
\hline $\boldsymbol{\eta}$ & $=0,322$ 4,302* & \\
\hline
\end{tabular}

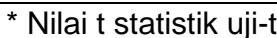

Sumber: Data primer yang diolah (2019).

Tabel 10 menunjukkan bahwa koefisien pengaruh integritas terhadap kualitas laporan hasil pemeriksaan sebesar 0,322 atau $32,2 \%$ sedangkan sisanya $67,8 \%$ merupakan pengaruh faktor-faktor lain diluar variabel eksogen yang diteliti.

Berdasarkan hasil pengujian, nilai thitung korelasi integritas sebesar 4,320 lebih besar dari $t_{\text {tabel }}(1,67303)$ sehingga $H_{1}$ diterima. Jadi berdasarkan hasil pengujian dapat disimpulkan bahwa integritas berpengaruh terhadap kualitas laporan hasil pemeriksaan.

\section{Pengaruh Skeptisisme Profesional Terhadap Kualitas Laporan Hasil Pemeriksaan}

Dari hasil menggunakan Software SmartPLS maka diperoleh persamaan struktural sebagai berikut: 
Tabel 10

Persamaan Struktural Skeptisisme Profesional Terhadap Kualitas Laporan Hasil Pemeriksaan

\begin{tabular}{|c|c|c|c|c|}
\hline $\begin{array}{l}\text { Endogenou } \\
\text { s Construct } \\
\text { Kualitas } \\
\text { Laporan } \\
\text { Hasil } \\
\text { Pemeriksaa }\end{array}$ & $=$ & $\begin{array}{c}\text { Eksogenou } \\
\text { s } \\
\text { Construct } \\
\text { Skeptisism } \\
\text { e } \\
\text { Profesional }\end{array}$ & + & $\begin{array}{c}\text { Error } \\
\text { Varianc } \\
e\end{array}$ \\
\hline$\eta$ & & $\begin{array}{l}0,252 \\
2,326^{*}\end{array}$ & + & 0,108 \\
\hline
\end{tabular}

${ }^{*}$ Nilai t statistik uji-t

Sumber: Data primer yang diolah (2019).

Tabel 10 menunjukkan bahwa koefisien pengaruh skeptisisme profesional terhadap kualitas laporan hasil pemeriksaan sebesar 0,252 atau 25,2\% sedangkan sisanya $74,8 \%$ merupakan pengaruh faktor-faktor lain diluar variabel eksogen yang diteliti.

Berdasarkan hasil pengujian, nilai thitung korelasi skeptisisme profesional sebesar 2,326 lebih besar dari $t_{\text {tabel }}$ $(1,67303)$ sehingga $H_{1}$ diterima. Jadi berdasarkan hasil pengujian dapat disimpulkan bahwa skeptisisme profesional berpengaruh terhadap kualitas laporan hasil pemeriksaan.

\section{Pengaruh Budaya Terhadap Kualitas Laporan Hasil Pemeriksaan}

Dari hasil menggunakan Software SmartPLS maka diperoleh persamaan struktural sebagai berikut:

Tabel 11

Persamaan Struktural Budaya Terhadap Kualitas Laporan Hasil Pemeriksaan

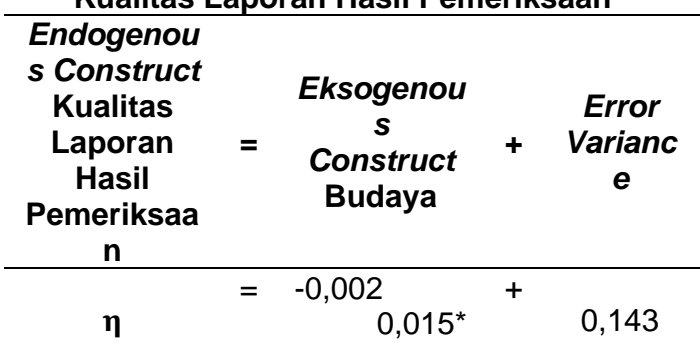

* Nilai t statistik uji-t

Sumber: Data primer yang diolah (2019).

Tabel 11 menunjukkan bahwa budaya yang dimiliki pemeriksa tidak memiliki pengaruh terhadap kualitas laporan hasil pemeriksaan.

Berdasarkan hasil pengujian, nilai $t_{\text {hitung }}$ korelasi budaya sebesar 0,015 lebih kecil dari $t_{\text {tabel }}(1,67303)$ sehingga $H_{1}$ ditolak. Jadi berdasarkan hasil pengujian dapat disimpulkan bahwa budaya tidak berpengaruh terhadap kualitas laporan hasil pemeriksaan.

\section{Pengaruh Kompetensi Terhadap Kualitas Laporan Hasil Pemeriksaan}

Dari hasil menggunakan Software SmartPLS maka diperoleh persamaan struktural sebagai berikut:

Tabel 12

Persamaan Struktural Kompetensi Terhadap Kualitas Laporan Hasil Pemeriksaan

\begin{tabular}{|c|c|c|c|c|}
\hline $\begin{array}{c}\text { Endogenous } \\
\text { Construct } \\
\text { Kualitas } \\
\text { Laporan } \\
\text { Hasil } \\
\text { Pemeriksaan } \\
\end{array}$ & $=$ & $\begin{array}{c}\text { Eksogenous } \\
\text { Construct } \\
\text { Kompetensi }\end{array}$ & + & $\begin{array}{c}\text { Error } \\
\text { Variance }\end{array}$ \\
\hline$\eta$ & & $\begin{array}{l}0,371 \\
3,774^{*}\end{array}$ & + & 0,098 \\
\hline
\end{tabular}

* Nilai t statistik uji-t

Sumber: Data primer yang diolah (2019).

Tabel 12 menunjukkan bahwa koefisien pengaruh kompetensi terhadap kualitas laporan hasil pemeriksaan sebesar 0,371 atau $37,1 \%$ sedangkan sisanya $62,9 \%$ merupakan pengaruh faktor-faktor lain diluar variabel eksogen yang diteliti.

Berdasarkan hasil pengujian, nilai $t_{\text {hitung }}$ korelasi kompetensi sebesar 3,774 lebih besar dari tabel $(1,6303)$ sehingga $\mathrm{H}_{1}$ diterima. Jadi berdasarkan hasil pengujian dapat disimpulkan bahwa kompetensi berpengaruh terhadap kualitas laporan hasil pemeriksaan.

\section{Pembahasan}

\section{Analisis Pengaruh Independensi Terhadap Kualitas Laporan Hasil Pemeriksaan \\ Hasil pengujian statistik} menyatakan bahwa variabel independensi 
berpengaruh terhadap kualitas laporan hasil pemeriksaan. Hasil penelitian ini sejalan dengan peneitian sebelumnya yang dilakukan oleh Samsi (2012) dan Tarungan (2016) yang menyatakan bahwa independensi memiliki hubungan positif dan berpengaruh signifikan terhadap kualitas laporan hasil pemeriksaan.

Independensi Inspektorat Daerah Kabupaten Subang diwujudkan dalam struktur organisasi pemerintah daerah. Kepala Inspektorat Daerah Kabupaten Subang bertanggungjawab langsung kepada Kepala Daerah/Bupati. Kepala Daerah/Bupati merupakan tingkatan tertinggi dalam pemerintahan daerah kabupaten. Penugasan Inspektorat Daerah Kabupaten Subang sudah ditetapkan dalam Piagam Audit Intern yang disahkan berdasarkan Peraturan Bupati Subang Nomor 18 Tahun 2017. Inspektorat Daerah Kabupaten Subang diberi akses untuk melakukan pengawasan. Auditor inspektorat dilarang merangkap jabatan sebagai pejabat structural dan tidak boleh terlibat langsung dalam operasional kegiatan auditee. Kualitas Laporan Hasil Pemeriksaan menjadi hal yang sangat penting karena akan dilaporkan kepada Kepala Daerah.

\section{Analisis Pengaruh Integritas Terhadap Kualitas Laporan Hasil Pemeriksaan}

Berdasarkan hasil penelitian, variabel integritas berpengaruh terhadap kualitas laporan hasil pemeriksaan. Hasil penelitian ini sejalan dengan Badjuri (2012) serta Queena dan Rohman (2012) yang menyatakan bahwa integritas berpengaruh positif dan signifikan terhadap kualitas laporan hasil pemeriksaan. Penelitian ini tidak sejalan dengan penelitian yang dilakukan oeh Sukriah (2009) yang menyatakan bahwa integritas tidak memiliki pengaruh terhadap kualitas laporan hasil pemeriksaan.
Salah satu fungsi Inspektorat Daerah Kabupaten Subang adalah memelihara dan meningkatkan kualitas tata kelola penyelenggaraan tugas dan fungsi instansi pemerintah. Hal ini akan terwujud jika integritas pemeriksa diterapkan dengan baik. Fakta integritas dan zona integritas di lingkungan Pemerintahan Kabupaten Subang telah ditandatangani Bersama termasuk inspektorat daerah. Hal ini dilakukan untuk mencapai visi besar Kabupaten Subang menuju Kabupaten Subang yang bersih, maju, sejahtera dan berkarakter. Dengan adanya penandatanganan fakta integritas ini maka Laporan Hasil Pemeriksaan akan semakin berkualitas karena inspektorat daerah merupakan pemeran kunci dalam pencapaian tujuan tersebut. Selain ini dalam Piagam Audit Intern juga disebutkan bahwa auditor Inspektorat Daerah Kabupaten Subang dalam melaksanakan pekerjaannya harus senantiasa mengacu pada standar audit intern pemerintah Indonesia dan Kode Etik profesi.

\section{Analisis Pengaruh Skeptisisme Profesional Terhadap Kualitas Laporan Hasil Pemeriksaan}

Variabel skeptisisme profesional berpengaruh positif terhadap kualitas laporan hasil pemeriksaan . Hasil penelitian ini sejalan dengan penelitian yang dilakukan Queena dan Rohman (2012) dan Tarungan (2016) yang menyatakan bahwa skeptisisme profesional memiliki hubungan positif dan signifikan terhadap kualitas laporan hasil pemeriksaan.

Berdasarkan hasil penelitian, pemeriksa Inspektorat Daerah Kabupaten Subang mempunyai sikap skeptisisme profesional yang termasuk dalam kategori baik tetapi pelaksanaannya masih harus ditingkatkan sehingga akan meningkatkan kualitas laporan hasil pemeriksaan. Inspektorat daerah merupakan salah 
auditor internal pemerintah. Pengawasan yang dilakukan oleh inspektorat daerah dapat dilakukan melalui audit, reviu, evaluasi, pemantauan, dan kegiatan pengawasan lainnya. Dalam melaksanakan tugasnya, inspektorat daerah harus memiliki sikap skeptisisme professional. Skeptisisme professional berarti mempunyai pemikiran yang selalu mempertanyakan dan melakukan evaluasi secara kritis terhadap bukti audit. Pemeriksa inspektorat daerah tidak boleh menganggap bahwa manajemen satuan kerja yang diperiksa tidak jujur, tetapi juga tidak boleh menganggap bahwa kejujuran manajemen satuan kerja yang diperiksa tidak diragukan lagi, walaupun sesama SKPD. Skeptisisme professional inilah yang mengakibatkan pemeriksa selalu berhati-hati dengan tetap menjaga kualitas laporan hasil pemeriksaan.

\section{Analisis Pengaruh Budaya Terhadap Kualitas Laporan Hasil Pemeriksaan}

Variabel budaya tidak

berpengaruh terhadap kualitas laporan hasil pemeriksaan.

Salah satu indicator budaya adalah jarak kekuasaan (Hofstede,2001). Indikator power distance yang digunakan adalah tingkat kesejahteraan (Armia, 2002) yang diukur dengan jumlah pegawai Inspektorat Daerah Kabupaten Subang yang berpendidikan minimal $S 1$. Jumlah pegawai Inspektorat Daerah Kabupaten Subang yang berpendidikan minimal S1 kurang dari $50 \%$, sehingga terdapat jarak kekuasaan yang tinggi.

Indicator yang digunakan dalam dimensi penghindaran ketidakpastian diukur dengan tingkat stress (Armia, 2002) pegawai inspektorat. Pegawai yang merasa nyaman dalam situasi yang sering mengalami perubahan berarti memiliki dimensi budaya penghindaran ketidakpastian yang rendah. Pilihan menjadi ASN/PNS merupakan bentuk penghindaran ketidakpastian karena tingkat PHK yang rendah. Hal ini berbeda dengan pegawai swasta yang menuntut persaingan yang lebih ketat karena tingkat PHK yang tinggi. Indicator yang digunakan dalam dimensi individualisme vs kolektivisme adalah keterlibatan individu dalam pencapaian tujuan organisasi (Armia, 2002).

Indicator yang digunakan dalam dimensi maskulinitas dan feminimitas adalah keseimbangan antara keluarga dengan pekerjaan. Dengan adanya keseimbangan antara keluarga dan pekerjaan mencerminkan kualitas hidup yang baik karena pada hakekatnya setiap orang pasti memerlukan keluarga dan salah satu cara untuk meningkatkan kesejahteraan keluarga adalah pekerjaan. Maskulinitas lebih menekankan pada kuantitas hidup sedangkan feminimitas lebih menekankan kepada kualitas hidup. Materialistis, ambisi dan kekuasaan merupakan nilai-nilai dimensi maskulinitas. Simpati kepada masyarakat bawah merupakan contoh dari dimensi feminimitas.

Indicator-indikator budaya tersebut di atas tidak berpengaruh terhadap kualitas laporan hasil pemeriksaan (kinerja pegawai inspektorat) karena pengangkatan dan pemberhentian pegawai inspektorat daerah dilakukan oleh pejabat pembina kapegawaian sesuai dengan ketentuan peraturan perundangundangan tentang pengangkatan dan pemberhentian PNS secara umum, tidak berdasarkan kualitas laporan hasil pemeriksaan.

\section{Analisis Pengaruh Kompetensi Terhadap Kualitas Laporan Hasil Pemeriksaan}

Variabel kompetensi berpengaruh terhadap kualitas laporan hasil pemeriksaan. Hasil penelitian ini sejalan dengan penelitian yang dilakukan Sukriah 
(2009) dan badjuri (2012) yang menyatakan bahwa kompetensi memiliki hubungan positif dan signifikan terhadap kualitas laporan hasil pemeriksaan. Tetapi tidak sejalan dengan penelitian yang dilakukan oeh Samsi (2012) yang menyatakan bahwa kompetensi tidak memiliki pengaruh terhadap kualitas laporan hasil pemeriksaan.

Piagam Audit Intern Kabupaten Subang menyebutkan bahwa syaratsyarat yang harus dipenuhi oleh auditor intern dalam hubungannya dengan kompetensi adalah memenuhi sertifikasi jabatan fungsional auditor; memiliki integritas dan perilaku professional, independent, jujur dan objektif dalam melaksanakan tugas; memiliki pengetahuan dan pengalaman mengenai teknis audit dan disiplin ilmu lain yang relevan dengan bidang tugasnya; bersedia meningkatkan pengetahuan, keahlian dan kemampuan profesionalismenya secara terus menerus. Syarat-syarat inilah yang mengakibatkan kompetensi berpengaruh terhadap kualitas laporan hasil pemeriksaan.

Analisis Pengaruh Independensi, Integritas, Skeptisisme Profesional, Budaya dan Kompetensi terhadap Kualitas Laporan Hasil Pemeriksaan.

Hasil uji $R^{2}$ dalam penelitian ini yaitu nilai koefieisen determinasi $\left(\mathrm{R}^{2}\right)$ kualitas laporan hasil pemeriksaan besar 0.521 dan termasuk kedalam kriteria determinasi moderate (Noviana, 2015). Hasil ini menunjukkan bahwa $52,1 \%$ variabel kualitas laporan hasil pemeriksaan dapat dipengaruhi oleh variabel independensi, integritas, skeptisisme professional, budaya dan kompetensi. Sedangkan sisanya sebesar $47,9 \%$ dipengaruhi oleh variabel lain yang tidak diteliti dalam penelitian ini.

\section{KESIMPULAN}

Kesimpulan dari penelitian ini adalah sebagai berikut:

1. Variabel independensi berpengaruh terhadap kualitas laporan hasil pemeriksaan.

2. Variabel integritas berpengaruh terhadap kualitas laporan hasil pemeriksaan.

3. Variabel skeptisisme profesional berpengaruh terhadap kualitas laporan hasil pemeriksaan.

4. Variabel budaya tidak berpengaruh terhadap kualitas laporan hasil pemeriksaan.

5. Variabel kompetensi berpengaruh terhadap kualitas laporan hasil pemeriksaan.

6. Variabel independensi, integritas, skeptisisme profesional, budaya dan kompetensi berpengaruh secara simultan berpengaruh terhadap kualitas laporan hasil pemeriksaan.

\section{REFERENCES}

\section{Peraturan Perundang-undangan}

Undang-undang Republik Indonesia Nomor 17 Tahun 2003 Tentang Keuangan Negara.

Peraturan Badan Pemeriksa Keuangan Republik Indonesia Nomor 1 Tahun 2017 tentang Standar Pemeriksaan Keuangan Negara (SPKN).

Peraturan Bupati Subang Tahun 2008 Tentang Tugas Pokok Dan Fungsi Inspektorat Daerah Kabupaten Subang.

Peraturan Menteri Dalam Negeri Nomor 4

Tahun 2008 Tentang Pedoman

Pelaksanaan Reviu Atas Laporan Keuangan Pemerintah Daerah.

Peraturan Menteri Dalam Negeri Nomor

21 Tahun $2011 \quad$ Tentang Perubahan Kedua Atas Peraturan Menteri Dalam Negeri Nomor 13 Tahun 2006 Tentang Pedoman Pengelolaan Keuangan Daerah. 
Peraturan Pemerintah Nomor 8 Tahun 2006 Tentang Pelaporan Keuangan Dan Kinerja Instansi Pemerintah.

Peraturan Pemerintah Nomor 60 Tahun 2008 Tentang Sistem Pengendalian Intern Pemerintah.

\section{Buku}

Ghozali. 2013. Aplikasi Analisis Multivariate Dengan Program IBM SPSS 21 Update PLS Regresi. Semarang: Universitas Diponegoro.

Ghozali. 2015. Partial Least Squares: Konsep Teknik dan Aplikasi Menggunakan Program SmartPLS 3.0. Semarang: Universitas Diponegoro.

Halim. 2015. Auditing Dasar-dasar Audit Laporan Keuangan, Edisi ke-VI, Cetakan ke-l. Yogyakarta: UUP STIM YKPN

Halim \& Damayanti. 2007. Pengelolaan Keuangan Daerah . Edisi: Kedua. Cetakan: Pertama. Yogyakarta: UPP STIM YKPN.

Mulyadi. 2002. Auditing Buku I, Edisi keVI, Cetakan ke-I. Jakarta: Salemba Empat.

Riduwan \& Kuncoro. 2014. Cara Menggunakan dan Memakai Path Analisis (Analisis Path). Bandung: Alfabeta.

Sugiyono. 2016. Metode Penelitian Kombinasi (Mixed Methods). Bandung: Alfabeta.

Sunyoto. 2013. Metode dan Instrumen Penelitian Ekonomi dan Bisnis. Yogyakarta: CAPS (Center for Academic Publishing Service).

Jurnal dan Artikel
Ahmad, dkk. 2011. Pengaruh Kompetensi dan Independensi Pemeriksa Terhadap Kualitas Hasil Pemeriksaan Dalam Pengawasan Keuangan Daerah: Studi kasus Pada Inspektorat Kabupaten Pasaman Sumatera Barat. Politeknik Negeri Padang.

Attamimi, Fikri M., dan Riduwan, 2015. Faktor-Faktor yang Mempengaruhi Skeptisisme profesional Auditor. Jurnal IImu \& Riset Akuntansi, Vol. IV, No. 7.

Ayuningtyas, Yulian, Harvita. 2012. Pengaruh Pegalaman Kerja, Independensi, Obyektifitas, Integritas dan Kompetensi Terhadap Kualitas Hasil Audit (Studi Kasus Pada Auditor Inspektorat Kota/Kabupaten di Jawa Tengah). Skripsi. Universitas Diponegoro Semarang.

Badjuri. 2012. Analisis Faktor-Faktor yang Mempengaruhi Kualitas Hasil Pemeriksaan Audit Sektor Publik: Stusi Empiris pada BPKP Perwakilan Jawa Tengah.

Badan Pemeriksaan Keuangan Negara Republik Indonesia. 2016. Ikhtisar Hasil Pemeriksaan Semester II Tahun 2016.

Badan Pemeriksaan Keuangan Negara Republik Indonesia Perwakilan Jawa Barat, Siaran Pers. Hasil Pemeriksaan atas LKPD TA 2014 Disclaimer, Opini LKPD TA 2104 Untuk Kabupaten Subang (24 Maret 2017).

Badan Pemeriksaan Keuangan Negara Republik Indonesia Perwakilan Provinsi DKI Jakarta, 2014. Hasil Pemeriksaan atas LK Pemerintahan Provinsi DKI Jakarta 
TA 2013 (24 Maret 2017). Diambil dari

http://jakarta.bpk.go.id/?p=3430, Jakarta.

Harahap, Lukman. 2015. Pengaruh Kompetensi, Independensi, Objektivitas dan Sensitivitas Etika Profesi Terhadap Kualitas Hasil Audit (Studi Kasus pada Auditor BPKP Daerah Istimewa Yogyakarta. Skripsi. Universitas Negeri Yogyakarta.

Harjanto. 2014. Pengaruh Kompetensi, Independensi, Obyektivitas, Akuntabilitas dan Integritas Terhadap Kualitas Audit dengan Etika Sebagai Variabel Moderasi. Skripsi: Universitas Diponegoro Semarang.

Hofstede, G.(2001). Culture's Consequences - Comparing Values, Behaviors, Institution, and Organizations Across Nations. California:Sage Publishing, Inc.

Riyunti, L(2017). Pengaruh Independensi, Integritas, dan Kompetensi terhadap Kualitas Hasil Reviu dengan Skeptisisme Profesional sebagai Variabel Intervening.

Nandari dan Latrini. 2015. Pengaruh Sikap Skeptis, Independensi, Penerapan Kode Etik dan Akuntabilitas Terhadap Kualitas Audit.

Noviana, Ayu, Citra. 2015. Pengaruh Pengetahuan Perpajakan, Pelayanan Fisikus dan Ketegasan Sanksi Perpajakan Terhadap Kepatuhan Dalam Memenuhi Kewajiban Pajak Penghasilannya Dengan Kesadaran Membayar Pajak Sebagai Variabel Intervening (Studi Kasuspada Pemilik Online Shop di Situs Tokopedia.com).
Oktania, Rina dan Bambang Suryono. 2013. Faktor-Faktor yang Berpengaruh terhadap Skeptisisme Profesional Auditor. Jurnal IImu \& Riset Akuntansi.

Pusdiklatwas BPKP. 2008. Modul Diklat Pembentukan Auditor Ahli: Kode Etik Dan Standar Audit. Bogor.

Queena dan Rohman. 2012. Analisis Faktor-Faktor yang Mempengaruhi Kualitas Audit Aparat Inspektorat Kota/Kabupaten di Jawa Tengah. Universitas Diponegoro.

Radio Republik Indonesia. 2016. DPRD Subang Tuding Irda Sebagai Penyebab Disclimer BPK Dua Tahun Berturut-turut (24 Maret 2017). Diambil dari www.rri.co.id/samarinda/post/berit a/291766/daerah/dprd subang.ht ml. Subang.

Republika. 2015. BPK Meminta Pemda Tingkatkan Kualitas Laporan Keuangan (20 Agustus 2017). Diambil dari http://m.republika.co.id/.

Tarungan, dkk. 2016. Pengaruh Skeptisisme Profesional, Kompetensi dan Independensi Auditor Terhadap Kualitas Hasil Pemeriksaan dalam Pengawasan Keuangan Daerah dengan Kepatuhan pada Kode Etik Sebagai Variabel Moderating.

Samsi, dkk. 2012. Pengaruh Pengalaman Kerja, Independensi dan Kompetensi Terhadap Kualitas Hasil Pameriksaan dengan Kepatuhan Etika Auditor Sebagai Variabel Pemoderasi.

Sukriah, dkk. 2009. Pengaruh Pengalaman kerja, Independensi, Obyektifitas, Integritas dan 
Kompetensi Terhadap Kualitas

Hasil Pemeriksaan.

Suraida. 2005. Pengaruh Etika Kompetensi, Pengalaman Audit dan Risiko Audit Terhadap Skeptisisme Profesional Auditor dan Ketepatan Pemberian Opini Akuntan Publik.

Zarefar,dkk. 2016. The Influence Of Ethics, Experience And Competency Toward The Quality Of Auditing With Professional Auditor Scepticism As A Moderating Variabel. 